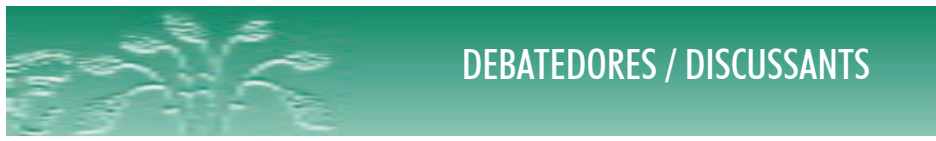

$10.12957 /$ demetra.2013.6904

\title{
A questão cultural na alimentação: mudanças e permanências
}

Food and culture: change and continuity

Luisa Ferreira da Silva'

1 Investigadora do Centro de Administração e
Políticas Públicas (CAPP), Instituto Superior
de Ciências Sociais e Políiticas (ISCSP) da
Universidade Técnica de Lisboa, Portugal.
É escolha da autora que a escrita não obedeça ao
Acordo Ortográfico
Correspondência / Correspondence
Luisa Ferreira da Silva
E-mail: luisafs@iscsp.utl.pt

\section{Ponto prévio}

O meu comentário abre necessariamente com um pedido de indulgência aos autores e aos leitores pelo meu atrevimento em aceitar o desafio para entrar neste debate. Move-me, em primeiro lugar, a relação académica e de amizade pela Maria Cláudia, com quem o meu percurso se cruzou há anos no seminário da Madel Luz. A perspectiva de trocarmos ideias sobre a problemática social da alimentação representa um movimento de aproximação intelectual que temos vindo a esboçar.

Que me desculpe o César Sabino, que também encontrei nos simpáticos 'salóes' atrás referidos, mas é sobretudo com a Maria Cláudia que vou dialogar. De verdade, apenas em ciência social da alimentação sinto alguma competência para propor pensamento. A teoria antropológica não é matéria de meu aprofundamento especializado, pelo que não tenho condições de contribuir com um questionamento criativo. 


\section{A estrutura do artigo}

O artigo de Sabino e Carvalho apresenta-se, na introdução, como uma leitura da escola estrutural-funcionalista com 'aproximações' ao campo da alimentação. Começa por rever a obra de Durkheim como 'Pai Fundador' e as de dois dos maiores representantes da antropologia social britânica, Radcliffe-Brown e Mary Douglas. Segue com a apresentação do trabalho de Monga sobre a comensalidade numa sociedade e cultura africana. Finaliza com uma síntese em que explicita o pensamento sobre a abordagem da mudança social pela escola estrutural-funcionalista.

Começarei por uma breve análise da estrutura do texto do ponto de vista dos seus fios condutores. Com efeito, precisei de a delinear com clareza, para mim própria, antes de organizar o pensamento sobre o que li. Na minha interpretação do artigo, ele tem como foco a temática da mudança social no estrutural-funcionalismo com o objectivo de mostrar que os autores dessa escola se pronunciaram sobre a mudança, contrariando a crítica que afirma o contrário, apontado como limitação a esta escola.

Complementarmente, associa-se o objectivo de relacionar a ciência social da alimentação, principalmente a sociológica, com os conhecimentos da teoria antropológica convocada. A mudança social como fio condutor não é claramente anunciada na Introdução, o que me dificultou a primeira leitura. Mas é a mudança o fio condutor de toda a escrita.

Do ponto de vista das introduções sobre alimentação, confesso que, de cada vez, elas me surpreenderam na leitura por aparecerem intempestivamente como entradas que interrompem o sentido do texto central (sobre a antropologia estrutural-funcionalista). Não que sejam desadequadas ou desinteressantes, antes pelo contrário. Mas, mais academicamente (o que tem defeitos e vícios, mas tem a vantagem da clareza), teria preferido que a alimentação constituísse um capítulo próprio em que se encarassem as implicações relacionadas entre os dois tópicos. Do ponto de vista do conteúdo também me parece que essa forma, mais 'arrumada', faria mais sentido, pois favoreceria o pensamento integrado sobre as questões levantadas.

\section{O tema da escrita: a mudança social como foco}

Desde o primeiro capítulo sobre Durkheim, em que se revê a estrutura e o funcionamento do social na sociedade moderna, o artigo dá centralidade ao tema da mudança social pela forma como se orienta para a noção de anomia.

É a este propósito que os autores introduzem a primeira questão relativa à comensalidade, sob a forma de convocação do autor (Fischler), que associou anomia e alimentação contemporânea. No artigo, esta referência é apresentada na forma de resumo das ideias deste autor, sem qualquer comentário por parte dos autores do artigo. Os autores virão a pronunciar-se mais adiante, só após 
a apresentação do trabalho de Radcliffe-Brown e da explicitação do seu (dos autores) pensamento relativamente à problemática da mudança social na abordagem estrutural-funcional - de novo, o foco na mudança. Aliás, 'Equilíbrio e Mudança' é o título deste novo capítulo.

O texto segue com dois capítulos dedicados ao pensamento de Mary Douglas, 'Estrutura Simbólica' e 'Mudança Estrutural entre os Leles do Kasai'. No conjunto, a obra de Mary Douglas é também orientada para o alvo da compreensão da mudança social. Começa por tratar da relação entre a lógica do pensamento e a lógica da organização do social, analisadas à luz da dimensão simbólica em que o par pureza / impureza é relevado enquanto resolução cultural do perigo que as sociedades atribuem à desordem. E continua pela análise da mudança social provocada pela ruptura do sistema simbólico derivada da adopção do cristianismo pelos Leles.

O último capítulo, 'Inventando a Tradição', apresenta o trabalho de Célestin Monga sobre a comensalidade numa sociedade e cultura africana, situando o seu carácter de codificação da violência simbólica e a adaptação do sistema por criação e re-criação. De novo, fica evidente que o que está em causa é a discussão do estrutural-funcionalismo do ponto de vista do tratamento que dá à mudança social.

\section{As aproximações à alimentação}

\section{Gastro-anomia, um sentido equivocado?}

Embora concordando com o pensamento exposto no artigo sobre os novos sentidos e significados que, nas sociedades contemporâneas, fazem ressurgir a comensalidade como um dos elementos fundamentais da coesão social, e portanto, aceitando que se possa considerar 'de certa forma equivocado' o conceito de gastro-anomia, pretendo alargar um pouco esta questão para o que me parece ser uma forma mais contextualizada no tempo.

O conceito de anomia - proposto por Durkheim para se referir ao culto do indivíduo com ausência de regras morais, característico das sociedades modernas - é, sem dúvida um conceito situado no tempo, o final do século XIX, em que a modernidade se começava a tornar visível como leitura de sociologia, isto é, no conjunto das suas implicações nas relações sociais. Não por acaso, foi esta a época que deu nascimento à sociologia, sendo Durkheim, com Marx e Weber, um primeiro autor.

A utilização do conceito hoje tem de ser adaptada à realidade do social contemporâneo em que a modernidade se radicalizou - identidade, reflexividade, risco, liquidez (1-3) - e desligada da visão moral imbuída compreensivelmente na proposta inicial. A sociologia desenvolveu outras perspectivas e muitos aprofundamentos e a própria sociedade evoluiu em mudanças extensas e intensas. Assim, quando usamos o termo de anomia, que considero ser uma referência útil do ponto 
de vista do discurso imagético sobre o social moderno (tal como classe operária ou burocracia, nas obras de Marx e de Weber), devemos explicitar a delimitação que lhe damos.

Desse ponto de vista, não tenho objecção ao conceito de gastro-anomia entendido na perspectiva do autor que o propõe (4): perda de contacto com o ciclo produtivo, perigo químico e outros (adições de açúcar, etc), alimentação individualizada, fim dos ritos familiares, restauração industrializada, liberdade de comer a todo o momento e em todos os locais. Ou seja, des-regulamentação da estrutura alimentar tradicional. Ao mesmo tempo, do ponto de vista dos novos desenvolvimentos da sociologia, concordo que se coloquem limites à utilização desse conceito já que ele apela à perda das regras morais (na expressão de Durkheim; nós hoje preferimos falar de relações sociais e de valores) em que assenta a coesão, sendo sabido (hoje) que as relações de comensalidade continuam a alimentar a coesão social. Mas isso significa que a alimentação contemporânea não é anómica ou que toda a sociedade o é e a alimentação, na sua estrutura e nas suas práticas, se adaptou à / adoptou à anomia, no processo de re-construção permanente a que o texto se refere a propósito de Radcliffe-Brown?

\section{Regras de higiene alimentar - a continuidade que subjaz à mudança}

Ainda a propósito da mudança social, o texto exemplifica o facto de que, 'alterando gradativamente a função de determinadas instituições, a sociedade acabaria por alterar a sua estrutura', com as mudanças que se verificam nas regras higiénico-sanitárias relativas à alimentação: da concepção que busca evitar o adoecimento, o discurso alimentar vem caminhando para a concepção de promoção da saúde.

Neste comentário não fica claro se os autores interpretam esta mudança no discurso como alteração da função que virá a provocar alteração na estrutura, ou se tomam a mudança do discurso por alteração na estrutura. É no sentido dessa clarificação que proponho a minha leitura.

As regras de higiene alimentar são uma manifestação do biopoder que assenta no saber da disciplina médica o poder de regular os corpos, domesticando-os na via da adaptação desejada ao funcionamento da sociedade (5). As determinações do biopoder são insidiosas, nada impondo à decisão individual. Elas actuam de forma 'microfísica', seduzindo o indivíduo para lhes obedecer de uma forma que ele percepciona como escolha sua, desejada por causa dos benefícios que espera alcançar (estéticos, de desempenho, de saúde, de longevidade, etc.).

O biopoder é uma característica estrutural que não é alterada pela mudança das regras higiénico-sanitárias. Pelo contrário, a adaptação das regras é devida ao novo saber sobre o corpo (ciência nutricional) e ao novo saber sobre os indivíduos (psicologia e sociologia), ou seja, é uma expressão reforçada do biopoder. É uma alteração que vai no sentido da maior eficácia da 
domesticação e da submissão à visão hegemónica da ciência e do poder capitalista que domina as sociedades, hoje, de uma forma global.

A ciência social não se pode equivocar tomando as modificações aparentes por mudanças estruturais ou até funcionais. Lembro os autores que foram eles que escreveram que, do ponto de vista da coesão social, a função da alimentação não se modificou, apesar da aparência de anomia.

\section{Uma ausência: o cerne da alimentação como cultura}

Refiro-me para começar ao capítulo 'Estrutura Simbólica' e à ausência do que considero ser o contributo 'clássico', porque de certa forma fundador, sobre o simbolismo de que estão imbuídas todas as culturas alimentares, desde logo pela definição que cada uma faz do que é um alimento, ou seja, o que é comestível e o que não o é (6). No mundo da modernidade avançada, nosso contemporâneo, em que está globalizado o acesso aos diversos tipos de alimentos com um alargamento imenso da variedade de alimentos, o que, senão a dimensão simbólica, explica as escolhas alimentares restritivas das diferentes identidades culturais (não comer carne de vaca, de porco, de cão, de macaco, de cobra, etc., entre tantos outros exemplos)?

Mary Douglas utilizou repetidamente a alimentação para analisar a dimensão simbólica da estrutura social, designadamente em 'Deciphering a Meal' (7), Para além da definição do comestível, os limites sociais descobrem-se nos horários de comer, na composição de cada refeição e na organização das refeições. Seja ao longo de cada dia, ao longo da semana, ou nos dias festivos do ano, as refeições obedecem a uma ordem padronizada. Fugir dessa ordem é entrar na desordem, nessa zona de perigo de abalo das estruturas, é ser contaminado pela impureza.

Anteriormente, Lévi-Strauss (6) tinha estabelecido o 'triângulo culinário' do cru, cozido e assado como simbolizando a oposição entre natural e cultural.

Posteriormente a Douglas, outros autores se debruçaram sobre os significados da alimentação e desenvolveram a compreensão das relações imbricadas que a cultura alimentar mantém com a organização social, seja na reprodução das hierarquias (8-10), como factor identitário (11, 12), enquanto significante da sociedade de risco (13), ou nas relações que mantém com 'o saudável'(14-16). Em todos estes domínios se descobre o simbolismo do puro / impuro, na forma como se limita o que é próprio de cada classe social (não levar alimentos à boca com as mãos quando se está à mesa ou ingerir pequenas quantidades de cada vez, num significado de secundarização da comida em relação à elegância, versus, por exemplo, limpar a boca nas costas da mão ou servir-se de grandes quantidades como manifestação de saber saborear o que se come), se define o que é a verdadeira comida (os alimentos que os emigrantes transportam consigo e os pratos tradicionais que se mantêm no país de acolhimento), se estabelece a relação de confiança existencial com o mundo exterior (retomar o consumo de um alimento que foi anunciado estar contaminado, exemplo de 'as vacas 
loucas', depois de a comunicação social afirmar que a situação estava controlada pelos especialistas) ou se realiza a escolha dos alimentos saudáveis (é saudável o que 'me' merece confiança porque é comercializado ou produzido por um familiar ou vizinho).

\section{O jocoso e a subversão das regras alimentares científicas}

No artigo, a entrada sobre alimentação e o simbólico surge a propósito da temática das relações jocosas como oportunidades paradoxais de reforço da ordem social pelo alívio da energia utilizada no autocontrolo da vida em sociedade. Os autores do artigo relacionam este facto social com a 'subversão eventual das regras alimentares' (p.19), vendo nela uma 'válvula de escape' à normatividade das regras nutricionais que constitui ao mesmo tempo um reforço das suas recomendações.

Concordando com a ideia desenvolvida no sentido de encarar como prática jocosa algumas das atitudes de subversão alimentar no quotidiano, ressalvo no entanto que nem toda a subversão alimentar remete para esse esquema de leitura. Em matéria alimentar, a jocosidade ritual - e é de ritual que se trata, não apenas de jocosidade - manifesta-se nas refeições de momentos festivos, esporádicos, como a refeição de Natal ou da Páscoa, ou de cerimónias de casamento, etc., em que, por ser festa, 'tudo' é permitido e não se deve pensar nas regras nutricionais.

No quotidiano, o que podemos entender como lado jocoso relativo à 'alimentação saudável científica' é a atitude irónica que consiste em conscientemente desvalorizar o risco com argumentos declaradamente falaciosos de que a própria pessoa se ri como que a comprovar que tem consciência da fragilidade do que afirma, do tipo 'sei que não devia comer disto, mas também não posso morrer à fome'.

Mas não me parece que a não submissão das escolhas alimentares quotidianas às recomendações da ciência médica e nutricional, tão generalizada na população, possa ser considerada nessa perspectiva do jocoso como ritual estruturado de aliviar tensões com a função social de reforçar a regra alimentar a que se refere. Dito de outra forma, não devemos tomar as 'regras' da ciência médica por 'regra social' no sentido do conjunto de regras que regem uma sociedade, ancoradas profundamente na sua cultura (o simbólico).

Do meu ponto de vista, a não submissão das escolhas alimentares quotidianas às recomendações da ciência médica e nutricional, na generalidade não conscientes (no sentido em que não trazidas à consciência como sendo não submissão) remetem para o simbolismo do indivíduo e do direito individual à liberdade de escolha como valor que orienta e organiza a sociedade de consumo (17, 18). Nesse princípio da escolha individual que estrutura os indivíduos nas sociedades modernas e que estrutura as próprias sociedades, a necessidade construída do consumo (indústria e publicidade) impõe-se às recomendações científicas. Articulada com o saber tradicional sobre os alimentos e a 
alimentação, essa não submissão configura uma resistência ao carácter cada vez mais extensivo e intensivo do biopoder como disciplina de vigilância e controlo.

Em termos de práticas alimentares, o paralelo interpretativo que se pode estabelecer com a jocosidade ritual reforçadora da regulação social, julgo que deve ser referido às regras alimentares tradicionais (Como as porcarias que me apetecer, porcarias, lixo alimentar, não é? E o que eu vou comendo benzinho é quando eu como na minha mão. (Mulher, 30 anos, escol. superior, médica) cit por (19). A comida caseira feita de refeições completas, em horários regulares, é a representação social que sai reforçada do estilo alimentar moderno feito de refeições que frequentemente são nãoeventos (comer só, ao balcão de um café, em dez minutos, por exemplo), em que se come, mas não se convive, em que se come, mas não se reproduz cultura (19). É com ela que os indivíduos identificam o saudável alimentar, ainda que ao nível cognitivo aceitem que o saudável alimentar é o definido pela ciência e o afirmem no discurso público (discurso para os outros). Lahire teorizou esta aparente contradição entre o que se crê e o que se faz, ou entre crenças contraditórias no património individual de disposições (20) .

\section{Alimentação e violência simbólica}

No último capítulo, 'Inventando a Tradição', é referido Bourdieu. Não conheço a obra do autor C. Monga a que o texto se refere, mas percebo que o seu trabalho é uma extensão aplicada da teoria de Bourdieu sobre a violência simbólica. Com efeito, na obra de Bourdieu sobre a distinção entre os grupos sociais, a alimentação é um dos temas centrais em que se descobre o exercício da violência simbólica. As maneiras de comer, de estar à mesa, de escolher os alimentos, são formas de distinção baseadas no habitus ou disposições incorporadas através das quais, juntamente com todos os outros saberes práticos (a instrução, a frequência de museus, as maneiras de vestir, etc.), as classes dominantes impõem às dominadas a sua supremacia e o desejo mimético de as copiarem.

$\mathrm{O}$ artigo não se debruça sobre este aspecto das sociedades modernas, o que seria muito interessante como contraponto à sociedade africana que é apresentada. Não estou certa de que a violência simbólica envolvida nas práticas alimentares seja 'aspecto mais demarcado em sociedades nas quais a fome e a miséria são condições extremas'. Porventura será ele mais impressionante e mais evidente aos olhos de quem observa do exterior. Mas não será esse apenas um efeito de ‘ilusão de óptica'? Para além dos escritos de Bourdieu, seria interessante fazer um levantamento na nossa sociedade, ou fazer pesquisa, se é que ainda não está feita, sobre os contornos que assume o exercício do poder através da alimentação. Re-apropriação de itens culturais alheios (alimentos globalizados, importados e até já produzidos localmente), rituais e cosmogonias tradicionais (as práticas alimentares das festas profanas e das religiosas; os alimentos de oferendas aos santos), a ostentação (banquetes e restaurantes associados a situações formais do tipo congressos profissionais, 
reuniões políticas, convites entre personalidades da finança, etc.), características encontradas na sociedade camaronesa, estão sem sombra de dúvida presentes nas nossas sociedades mais avançadas na modernização, também com sentidos específicos, adequados aos costumes hierárquicos locais e por vezes subvertendo-os.

\section{Considerações finais}

Mais uma vez, desculpem a insistência, mas considero importante assinalar: 'a mudança no esquema teórico tratado' (p.27) aparece como o elemento nuclear que agrega o texto. Se insisto neste ponto, é para sugerir aos autores que reformulem a Introdução para que transmita um enquadramento adequado orientador da leitura e facilitador do acompanhamento do vosso pensamento.

De forma semelhante, seria interessante que na Introdução se explicitasse melhor o trabalho que é feito de relacionação da temática da alimentação com a teoria antropológica cuja finalidade, diria eu, não é apenas a de motivar à interdisciplinaridade como aí é afirmado. Esta é apenas um meio para realizar um diálogo informado da sociologia da alimentação com a teoria antropológica.

Resta-me agradecer a oportunidade que me deram de pensar sobre esta matéria e felicitar-vos pela iniciativa. Propor um texto para debate é uma boa via para o diálogo construtivo em matéria de conhecimento.

\section{Referências}

1. Bauman Z. Modernidade Líquida. Rio de Janeiro: Zahar; 2001.

2. Beck U. La Sociedad del riesgo. Barcelona: Paidós; 1998.

3. Giddens A. As Consequências da modernidade. Oeiras: Celta; 2002.

4. Fischler C. Gastro-nomie et gastro-anomie sagesse du corps et crise bioculturelle de l'alimentation moderne. Communications. 1979;31:189-210.

5. Foucault M. Le Souci de Soi: Histoire de la Sexualité 2. Paris: Gallimard; 1984.

6. Lévi-Strauss C. Mythologiques: Le cru et le cuit. Librairie Plon; 1964.

7. Douglas M. Deciphering a Meal. In: Counihan C, Esterik PV (ed.). Food and Culture a Reader. New York; London: Routledge; 1997. p. 36-54.

8. Bourdieu P. La Distinction: critique sociale du jugement. Paris: Les Editions de Minuit; 1979.

9. Goody J. Cozinha, culinária e classes. Lisboa: Celta; 1998. 
10. Grignon C, Grignon C. Consommationns Alimentaires et Styles de Vie: Contribution à l'étude du goût populaire. Institut National de la Recherche Agronomique Centre National de la Recherche Scient. 1980 Sept:50-81.

11. Calvo M. Des Pratiques Alimentaires. Economie Rurale. 1983;154:44-7.

12. Valagão MM. Práticas Alimentares dos Emigrantes, Mudança ou continuidade? Sociedade e Território. 1989 fev;3:81-91.

13. Lupton D. Food, risk and subjectivity. In: Williams SJ, Gabe J, Calnan M, editors. Health, medicine and society Key theories, future agendas. London; New York: Routledge; 2000. p. 366:205-18.

14. Calnan M. Food and health: a comparison of beliefs and practices in middle-class and working-class housebolds. In: Cunnigham-Burley S (ed.). Readings in Medical Sociology. Londres: Routledge; 1990. p. 261: 9-36.

15. Delormier T, Frohlich KL, Potvin L. Food and eating as social practice: understanding eating patterns as social phenomena and implications for public health. Sociol Health Illn. 2009;31(2):215-26.

16. Silva LFD. A Saúde e o saudável nas racionalidades leigas: o caso da alimentação. In: Carapinheiro GO (ed.). Sociologia da Saúde Estudos e Perspectivas. Lisboa: Pé de Página; 2006. p. 165-95.

17. Baudrillard J. A sociedade de consumo. Lisboa: Edições 70; 2007.

18. Featherstone M. Consumer Culture \& Postmodernism. SAGE Publications; 1991.

19. Silva LFD. Saber Prático de Saúde: as lógicas do saudável no quotidiano. Porto: Afrontamento; 2008.

20. Lahire B. Patrimónios Individuais de Disposições: para uma sociologia à escala individual. Sociologia, Problemas e Práticas. 2005(49):11-42. 
